\title{
Postprandial Glycemia and Cardiovascular Disease in Diabetes Mellitus
}

\section{atualização}

\section{BERNARDO LÉO WAJCHENBERG}

Endocrine Service and Diabetes and Heart Center of The Heart Institute, Hospital das Clínicas of The University of São Paulo Medical School, São Paulo, SP.

\begin{abstract}
This article reviews the role of fasting and postprandial glycemia to the overall glycemic control of patients with type 2 diabetes and glucose intolerance, as well as their causal relationship upon micro and macrovascular complications. Recent studies have suggested that a third component of the glucose triad, the postprandial glucose excursions, might have a role in the overall glycemic load and might also reflect glycemic control. Epidemiological and intervention studies are presented in the article, supporting the conclusion that postprandial hyperglycemia in impaired glucose tolerance and diabetic subjects is a more powerful marker of cardiovascular disease risk than fasting hyperglycemia, then the treatment directed at specifically lowering postprandial glucose is crucial, as underlined by the American Diabetes Association. (Arq Bras Endocrinol Metab 2007;51/2:212-221)
\end{abstract}

Keywords: Diabetes mellitus; Impaired fasting glucose; Glucose intolerance; Cardiovascular disease; Postprandial glycemia

\section{RESUMO}

Glicemia Pós-Prandial e Doença Cardiovascular no Diabetes Mellitus. O presente artigo revisa o papel da glicemia de jejum e pós-prandial em relação ao controle glicêmico de pacientes com diabetes do tipo 2 e com intolerância à glicose, assim como sua relação causal sobre as complicações micro e macrovasculares. Estudos recentes têm sugerido que um terceiro componente na tríade glicêmica, as excursões glicêmicas pósprandiais, podem ter influência sobre a carga glicêmica total, e podem também refletir sobre o controle glicêmico. Estudos epidemiológicos e de intervenção são apresentados neste artigo, suportando a conclusão de que a hiperglicemia pós-prandial na intolerância à glicose e em pacientes com diabetes é um marcador mais potente de risco cardiovascular do que a hiperglicemia de jejum, portanto o tratamento dirigido especificamente para reduzir a glicemia pós-prandial é crucial, conforme sugerido pela American Diabetes Association. (Arq Bras Endocrinol Metab 2007;51/2:212-221)

Descritores: Diabetes mellitus; Glicemia de jejum alterada; Intolerância à glicose; Doença cardiovascular; Glicemia pós-prandial

U NTIL RECENTLY, THE EXACT contributions of fasting and post-prandial glycemia (PPG) to the overall glycemic control of patients with type 2 diabetes (DM2) remained largely undetermined (1). Because this issue has not been clearly resolved, both hemoglobin Alc (HbAlc) and fasting plasma glucose (FPG) have been considered valid markers for overall glucose exposure and thus were routinely used to evaluate glucose con-
Recebido em 06/17/07 Aceito em 11/01/07 
trol of diabetes (2). Recent studies, however, have suggested that a third component of the glucose triad, the PPG excursions, might have a role in the overall glycemic load and might also reflect glycemic control $(3,4)$. Furthermore, it was found that HbAlc is a function of both FPG and PPG (5).

Many of the diabetics develop diabetes-specific microvascular pathology in the retina, renal glomerulus and peripheral nerves and accelerated atherosclerotic macrovascular disease affecting arteries that supply the heart, brain and lower extremities. Indeed, DM2 have a considerable enhanced risk of cardiovascular disease: the risk is two to fourfold for men and women, respectively, compared to non-diabetic persons (6). This excess risk is not fully explained. Less than half of this excess risk can be attributed to the higher prevalence of classic risk factors, as for example dyslipidemia (high triglycerides, low HDL-cholesterol) and hypertension (7). Similarly, cardiovascular disease has now overtaken diabetic nephropathy as the leading cause of premature mortality in young adults with childhood-onset type 1 diabetes. Carotid intima-media thickness was also increased in these patients and resembled that observed in non-diabetic individuals who were $20-30$ years older (8).

Since the increased cardiovascular risk in diabetic patients is not explained by the classic risk factors, it is thought to be related to hyperglycemia (9), particularly in children and adolescents with diabetes in whom the majority have suboptimal blood glucose control. This is one of the main reasons, besides prevention, delay, or arrest of microangiopathic complications, why the correction of hyperglycemia is the primary aim in diabetes care, a poor control of hyperglycemia appearing to play a significant role in the development of cardiovascular disease (CVD) in diabetes (10).
In patients with well controlled diabetes ( HbAlc $<7 \%$, or within $1 \%$ of normal) or glucose intolerance (normal FPG and a 2-hour plasma glucose of 140 to $200 \mathrm{mg} / \mathrm{dl}$, after $75 \mathrm{~g}$ oral glucose), postprandial hyperglycemia has a greater effect on HbAlc than FPG, as shown by Monnier and Colette (11), who observed, by using the diurnal glycemic profile, that PPG is the predominant contributor in patients with satisfactory to good control of diabetes, whereas the contribution of FPG increases with worsening diabetes. Therefore, in patients with elevated HbAlc, the PPG may play a disproportionate lesser role in the genesis of both microvascular and macrovascular complications of diabetes (12).

Several epidemiological studies in the past 20 years have shown an association between the 2 -hour plasma glucose, post $75 \mathrm{~g}$ oral glucose load, and the occurrence of CVD in the general population (13). A meta-analysis of published data from 20 studies of 95,783 individuals who had 3,707 cardiovascular events over 12,4 years confirmed the association between 2-hour glucose levels after an oral glucose load and incident cardiovascular events (14). In figure 1 , it is indicated the exponential regression model which provided the best fit for the data. Compared with the reference fasting glucose of $75 \mathrm{mg} / \mathrm{dl}$ (relative risk, $\mathrm{RR}=1.0$ ), a fasting glucose of $110 \mathrm{mg} / \mathrm{dl}$, the threshold value for the classification of impaired fasting glucose (at the time the study was performed) was associated with a RR of cardiovascular events of 1.33 (95\% CI 1.06-1.67); 2-hour glucose of $140 \mathrm{mg} / \mathrm{dl}$, the threshold value for impaired glucose tolerance was associated with a RR of cardiovascular events of 1.58 (95\% CI 1.19-2.10). After removal of any glucose values in the diabetic range, the exponential relationship

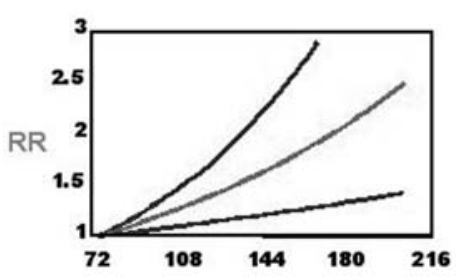

$2 \mathrm{~h}$ Glucose

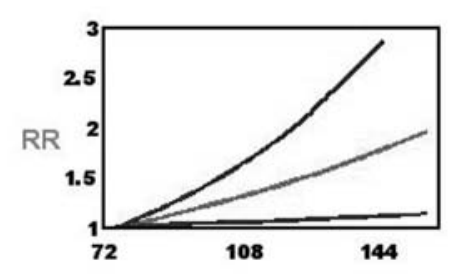

Fasting Glucose

$2 h$ G = 140: $R R=1.58(1.19-2.10)$ $\mathrm{mg} / \mathrm{dl}$

Fasting $G=110: R R=1.33(1.06-1.67)$

After removal any $D M: P=\mathbf{0 . 0 0 0 6 4}$ for $\mathbf{2} \mathrm{h} \mathbf{G}$

$P=\mathbf{0 . 0 5 6}$ for FPG

Figure 1. Meta-regression curves and $95 \% \mathrm{Cls}$ (confidence intervals) of fasting and 2-h glucose values (compared with the reference fasting glucose of $72 \mathrm{mg} / \mathrm{dl}$ ) vs. $\mathrm{RR}$ (relative risk) of $\mathrm{CV}$ events. [Modified from Coutinho $\mathrm{M}$ et al. Diabetes Care 1999;22:233-40 (ref. 14)]. 
was maintained. There was a suggestive trend $(\mathrm{P}=$ $0.056)$ between fasting glucose and cardiovascular events, as there was a significant relationship between 2 -hour glucose $(\mathrm{P}=0.00064)$ and the occurrence of cardiovascular events. This and other studies provide support for the hypothesis that non-diabetic degrees of fasting and postprandial hyperglycemia are associated with CVD, and that dysglycemia (i.e., any persistent elevation in glycemia) is a cardiovascular risk factor.

Plasma glucose is a continuous risk factor for $\mathrm{CVD}$, in both diabetic and non-diabetic people, the risk extending below impaired fasting and impaired glucose tolerance cutoffs. Therefore, dysglycemia should be added to the list of established continuous cardiovascular risk factors, such as blood pressure and LDL-cholesterol. Postprandial plasma glucose appears to be the earliest dysglycemic marker for CVD risk (15).

In a similar way, the relationship between HbAlc, CVD and total mortality was evaluated in the Norfolk cohort of the European Prospective Investigation into cancer and nutrition (EPIC-Norfolk), a study that followed 4,662 men and 5,570 women, 45 to 79 years-old, residents of Norfolk, United Kingdom. $\mathrm{HbAlc}$ and CVD risk factors were assessed from 1995 to 1997 and CVD events and mortality were assessed during the follow-up period until 2003. In men and women, the relationship between HbAlc and CVD (806 events) and between HbAlc and all-cause mortality (521 deaths) was continuous and significant throughout the whole distribution. The relationship was apparent in persons without known diabetes. Persons with $\mathrm{HbAlc}$ less than $5 \%$ had the lowest rates of CVD and mortality. An increase in HbAlc of $1 \%$ was associated with a RR of death from any cause of 1.24 (95\% CI 1.14 to $1.34 ; \mathrm{P}<0.001)$ in men and with a RR of 1.28 (95\% CI 1.06 to $1.32 ; \mathrm{P}<0.001)$ in women. These RRs were independent of age, body mass index, waist-to-hip ratio, systolic blood pressure, serum cholesterol, cigarette smoking and history of CVD. Fifteen percent (68 of 521) of the deaths in the sample occurred in diabetics, but $72 \%$ (375 of 521) occurred in persons with $\mathrm{HbAlc}$ between $5 \%$ and $6.9 \%$. However, whether or not HbAlc concentrations and CVD are causally related cannot be concluded from an observational study (16). Of interest are the patients with isolated postprandial hyperglycemia, in whom about a twofold risk of CVD was found (17).

Two important questions arise from these observations as put forward by Heine and Dekker (13): Is postprandial hyperglycemia an independent risk factor, i.e., causally related to CVD, to which the enhanced risk can fully be attributed? If so, do we need to consider the enhanced meal-related glucose excursions as a treatment target in patients with DM2? Alternatively, postprandial hyperglycemia might just be a marker for the increased risk of CVD. In that case, other factors need to be identified which can explain the epidemiological observations. From the presently available data, since the review from Heine and Dekker was published in 2002 (13), epidemiological and observational studies, it can be stated that despite postprandial hyperglycemia being an independent risk factor for CVD other metabolic risk factors are frequently associated with the postprandial state, such as high concentrations of triglyceride-rich lipoproteins, are also present (13).

\section{MECHANISMS OF POSTPRANDIAL HYPERGLYCEMIA}

The loss of the acute (0-10 minutes) insulin secretion, after an intravenous glucose injection, which correlates with the first-phase insulin response during the hyperglycemic clamp, characterizes the postprandial hyperglycemia, as well as the impaired fasting glucose, while subjects with elevated PPG also have impaired latephase insulin secretion, after 20 minutes of that clamp. Furthermore, subjects with postprandial hyperglycemia have marked peripheral insulin resistance with only mild hepatic insulin resistance. On the other hand, in IFG there is severe hepatic insulin resistance and normal or near-normal clamp-determined peripheral insulin sensitivity $(18,19)$. Despite late hyperinsulinemia, at 30 minutes after an oral glucose challenge, the impaired glucose tolerance results primarily from reduced suppression of hepatic glucose output due to abnormal pancreatic islet-cell function (smaller increases in plasma insulin and smaller reductions in plasma glucose in comparison with normal subjects, both $\mathrm{P}<0.01)(20)$.

\section{DELETERIOUS EFFECTS OF THE POSTPRANDIAL HYPERGLYCEMIC EXCURSIONS}

Most cardiovascular risk factors are affected directly by an acute increase of glycemia, such as (21) increase in LDL oxidation and endothelial dysfunction (vasoconstriction and decreased vasodilating response to stimuli), probably linked with a reduced production/bioavailability of nitric oxide (NO), since hyperglycemiainduced endothelial dysfunction is counterbalanced by arginine. Also observed are increased production of 
collagen from the mesangial cell, activation of blood coagulation that is likely to cause thrombosis, increase in blood pressure, increase in the circulating levels of intracellular adhesion molecule 1 (ICAM-1), thus activating one of the first stages of the atherogenic process, increase in inflammation, increased production of plasma interleulin-6, interleukin-18 and tumor necrosis factor- $\alpha$ (TNF- $\alpha)$, considering that the concept of atherosclerosis as an inflammatory disease even in diabetes is now well established.

Considering the increase in oxidative stress, hyperglycemia induces an overproduction of superoxide by the mitochondrial electron-transport chain. Superoxide overproduction is accompanied by increased nitric oxide (NO) generation, due to endothelial NO synthase (eNOS) and inducible NO synthase (iNOS) uncoupled state, favoring the formation of the strong oxidant peroxynitrite, which in turn damages DNA. DNA damage will result in acute endothelial dysfunction that, convincingly, contributes to the development of CVD. Several indirect (use of antioxidants) and direct (estimate of the effects of acute hyperglycemia on oxidative stress markers, such as nitrotyrosine overgeneration, which is an independent predictor of CVD) evidences support the concept that acute hyperglycemia works through the production of an oxidative and nitrosative stress. The presence of increased oxidative stress also activates pathways regulated by the transcription factor nuclear factor- $\mathrm{K} \beta$ (NF-K $\beta$ ), which is known to have a central role in the pathogenesis of late diabetic complications. Other known effects of postprandial hyperglycemic peaks are the reduction in retinal perfusion and increase in the glomerular filtration rate.

\section{POSTPRANDIAL TRIGLYCERIDE CONCENTRATIONS AS PREDICTORS OF CVD}

Plasma triglyceride (TG) levels are generally increased for 3-6 hours after a meal, and once postprandial hypertriglyceridemia occurs it is exacerbated by the next meal and persists for the entire day. Indeed, postprandial hypertriglyceridemia is a frequent feature in DM2, even in patients with apparently normal fasting TG values of less than $2.2 \mathrm{mmol} / \mathrm{l}(<195 \mathrm{mg} / \mathrm{dl})$. After breakfast the TG concentrations gradually rise to peak concentrations between dinner and bedtime. The long duration of the so-called postprandial state can probably be explained by the insulin resistant state. Postprandial hypertriglyceridemia and the associated atherogenic alterations of the lipoproteins are consid-

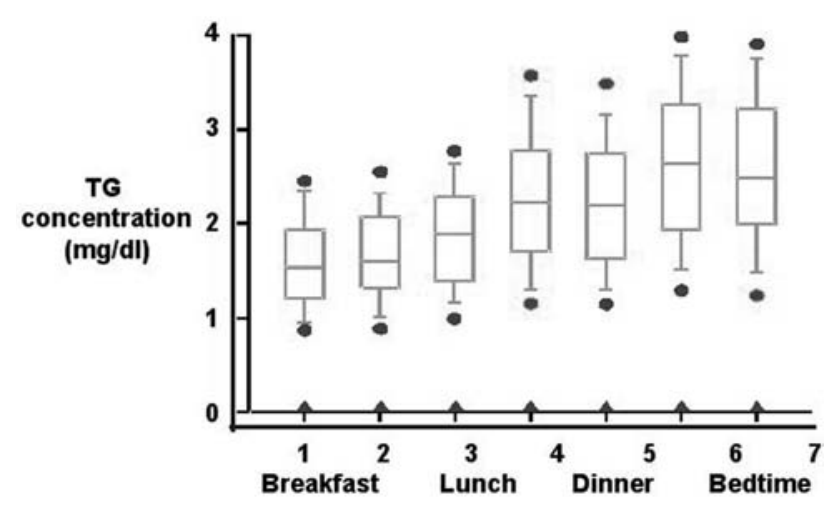

Figure 2. Home measured postprandial TG levels in normotriglyceridemic "free-living" persons with type 2 diabetes. [Heine RJ, Dekker JM. Diabetologia 2002;45:461-75 (ref. 13)].

ered to be part of the insulin resistant state (22), also found in the postprandial hyperglycemic state, as indicated before.

In an observational study of 145 DM2 patients and 30 non-diabetic subjects of the same geographical area (near Naples, Italy), 61\% of DM2 had TG values higher than $200 \mathrm{mg} / \mathrm{dl}$ (a value found to be linked to a greater intima-media thickness of the carotid artery in DM2, as observed by Teno et al.) 3 hours after lunch and $49 \%$ before dinner; $23 \%$ of the diabetics had normal fasting TG values $(<150 \mathrm{mg} / \mathrm{dl})$. In the control group the percentage of subjects with a TG value above $200 \mathrm{mg} / \mathrm{dl}, 3$ hours after lunch and before dinner was $17 \%(23)$.

There is the question of whether postprandial hypertriglyceridemia, which rises concomitantly with postprandial hyperglycemia, is a true CVD risk factor (13). However, evidence suggests that postprandial hypertriglyceridemia and hyperglycemia independently induce endothelial dysfunction through oxidative stress (24). The known inverse association between HDL-cholesterol and TG makes it very difficult to determine whether TG is an independent risk factor for atherosclerotic vascular disease. A meta-analysis including data of 46,413 men and 10,864 women from 17 published reports of population-based prospective studies, showed that the TG concentration is an independent risk factor for CVD, also when adjusted for HDL-cholesterol (25). A 1 mmol/l (88 $\mathrm{mg} / \mathrm{dl}$ ) increase was associated with a relative risk of 1.3 for men and 1.8 for women.

Another study, applying a nested case-control design on the data from 14,916 men aged 40 to 84 years in the Physicians Health Study, showed that non-fasting TG levels were a strong and independent predictor of future risk of myocardial infarction. In 
contrast, LDL particle diameter was associated with risk of myocardial infarction, but not after adjustment for TG level. The known interrelations between HDLcholesterol, TG and LDL size could be shown, reflecting the underlying metabolic disturbance, i.e., insulin resistance or metabolic syndrome. The authors concluded that TG concentrations are an important indicator of risk and can therefore be used as such (26).

Several clinical studies in non-diabetics have also suggested that high postprandial TG-rich lipoproteins are related to coronary heart and/or carotid artery disease. Moreover, an association could be shown between postprandial chylomicron remnants and the progression of angiographically determined coronary heart disease (13).

The associations between postprandial TG concentrations and the carotid intima-media thickness by ultrasonography (predictive of incident coronary artery heart disease) in diabetic and non-diabetic populations, support the concept that atherosclerorosis is a postprandial phenomenon (22).

\section{POSTPRANDIAL HYPERGLYCEMIA AND MACROVASCULAR (CARDIOVASCULAR) COMPLICATIONS}

\section{Epidemiological evidences}

The oral glucose tolerance test (OGTT) has been mostly used in epidemiological studies to evaluate the risk of CVD. The advantage of the OGTT is its simplicity: a single plasma glucose measurement 2 hours (2-hr) after the glucose load to determine whether the glucose tolerance is normal, impaired or indicative of overt dia- betes. The caveats of the OGTT are numerous, because $75 \mathrm{~g}$ or $100 \mathrm{~g}$ glucose is almost never ingested during a meal and many events associated with ingesting glucose do not incorporate the numerous metabolic events associated with eating a mixed meal. However, it has been recently demonstrated that the OGTT may represent a valid tool to reveal carbohydrate metabolism during a standardized mixed meal (27).

From the epidemiological point of view, the Hoorn Study (28), the Honolulu Study (29), the Chicago Heart Study (30), and the DECODE (Diabetes Epidemiology: Collaborative analysis of Diagnostic Criteria in Europe) study (31) have shown that the glucose serum level 2-hr after an oral glucose challenge is a powerful predictor of cardiovascular risk. A further analysis of the DECODE data focusing on CVD $(268,811$ person-years $)$ showed that, after adjusting for possible confounders, and with FPG and 2 -hour glucose in the same model, the RR of CVD was not significantly increased in subjects with a FPG $\geq 126 \mathrm{mg} / \mathrm{dl}$ than in those with a FPG $<110 \mathrm{mg} / \mathrm{dl}$ (the cutoff for normal FPG levels at the time of publication) (RR $1.2095 \%$ CI $0.88-1.64, \mathrm{P}=\mathrm{NS}$ ). On the contrary, the risk of CVD mortality in subjects with 2 hr OGTT plasma glucose $\geq 200 \mathrm{mg} / \mathrm{dl}$ was $1.40(95 \%$ CI 1.02-1.92, $\mathrm{P}<0.005)$ compared with those with 2hr OGTT < $140 \mathrm{mg} / \mathrm{dl}$. Therefore, FPG was not an independent predictor of CVD mortality when the multivariate analysis included both FPG and post-challenge plasma glucose. In this analysis, only the latter turned out to be an independent predictor of CVD mortality (32). All these evidences were confirmed by Coutinho et al. (14) meta-analysis, already presented, and by another one which involved more than 20,000

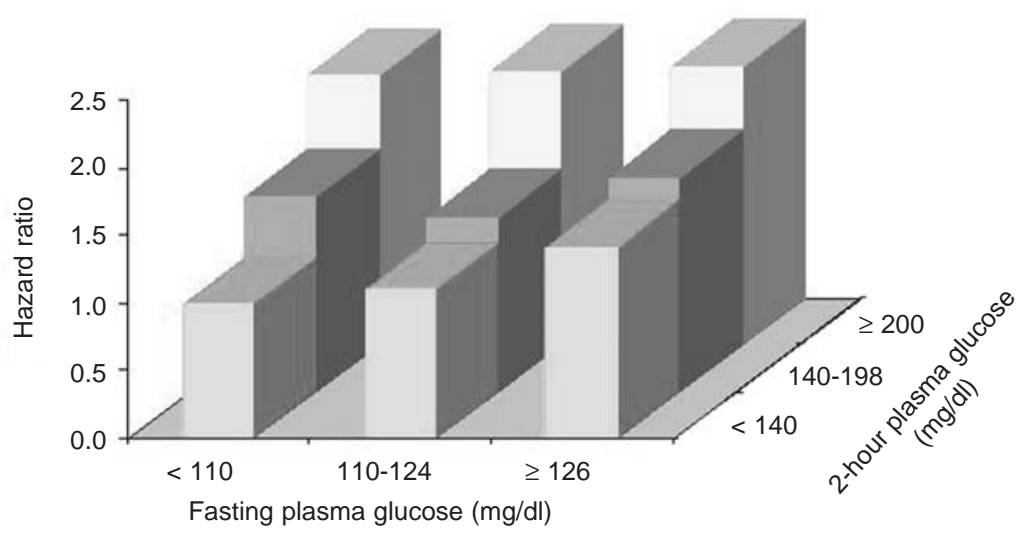

Adjusted for age, center, sex, cholesterol, BMI, SBP, smoking

Figure 3. Relative risk for all-cause mortality in subjects not known as diabetic (DECODE). [Adapted from DECODE Study Group. Lancet 1999;354:617-21 (ref. 31)]. 
subjects, by pooling the data of the Whitehall Study, Paris Prospective Study, and Helsinki Policemen Study (33). The possible role of postprandial hyperglycemia as independent risk factor has been supported by the Diabetes Intervention Study, which showed that postprandial glycemia, but not fasting glucose, predicts infarction in DM2 subjects (34) in full agreement with studies on clinical CVD, echo-duplex scanning of the carotids documented the association of postprandial hyperglycemia with medio-intimal thickening (marker of atherosclerosis) (35).

\section{POSTPRANDIAL HYPERGLYCEMIA AND MICROVASCULAR COMPLICATIONS}

\section{Epidemiological evidences}

The uncontrolled glycemic peaks inducing overproductions of superoxide activates 4 major pathways of hyperglycemic damage to the tissues: the polyol pathway, advanced glycation end products (AGE) formation, activation of protein kinase $\mathrm{C}$ isoforms and the hexosamine pathway (36). The activity of protein kinase $C$ (isoform $\beta$ ) impairs contraction of smooth muscle cells or pericytes, increases production of basement membrane materials and enhances cell proliferation and capillary permeability. Thus, activation of protein kinase $\mathrm{C}-\beta$ by postprandial hyperglycemia could be responsible by microvascular complications that may be developing even in the early stages of diabetes (37). According to Vinik, although macrovascular complications, such as myocardial infarction, stroke and gangrene, are only partially attributable to hyperglycemia and its attendant effect, the microvascular complications including retinopathy, nephropathy and neuropathy are directly related to the degree of hyperglycemia (38).

Data from the National Health and Nutrition Examination Survey (NHANES) III showed that patients who had 2-hour postprandial glucose levels of $194 \mathrm{mg} / \mathrm{dl}$ had a three-fold increase in incidence of retinopathy, despite normal fasting glucose levels (fasting plasma glucose $<110 \mathrm{mg} / \mathrm{dl}$, at the time of the study). Studies of Pima Indian and Egyptian populations revealed a similar increase in the incidence of retinopathy in subjects with normal fasting glucose levels $(<110 \mathrm{mg} / \mathrm{dl})$, but 2 -hour postprandial glucose values of $>200 \mathrm{mg} / \mathrm{dl}$ (39).

\section{POSTPRANDIAL HYPERGLYCEMIA AND CVD}

\section{Intervention studies}

The STOP-NIDDM trial has shown that treatment of subjects with impaired glucose intolerance with the aglucosidase inhibitor acarbose, which specifically reduces postprandial hyperglycemia, was associated not only with a $36 \%$ reduction in the risk of progression to diabetes ( 40 ), but also with a $34 \%$ risk reduc-

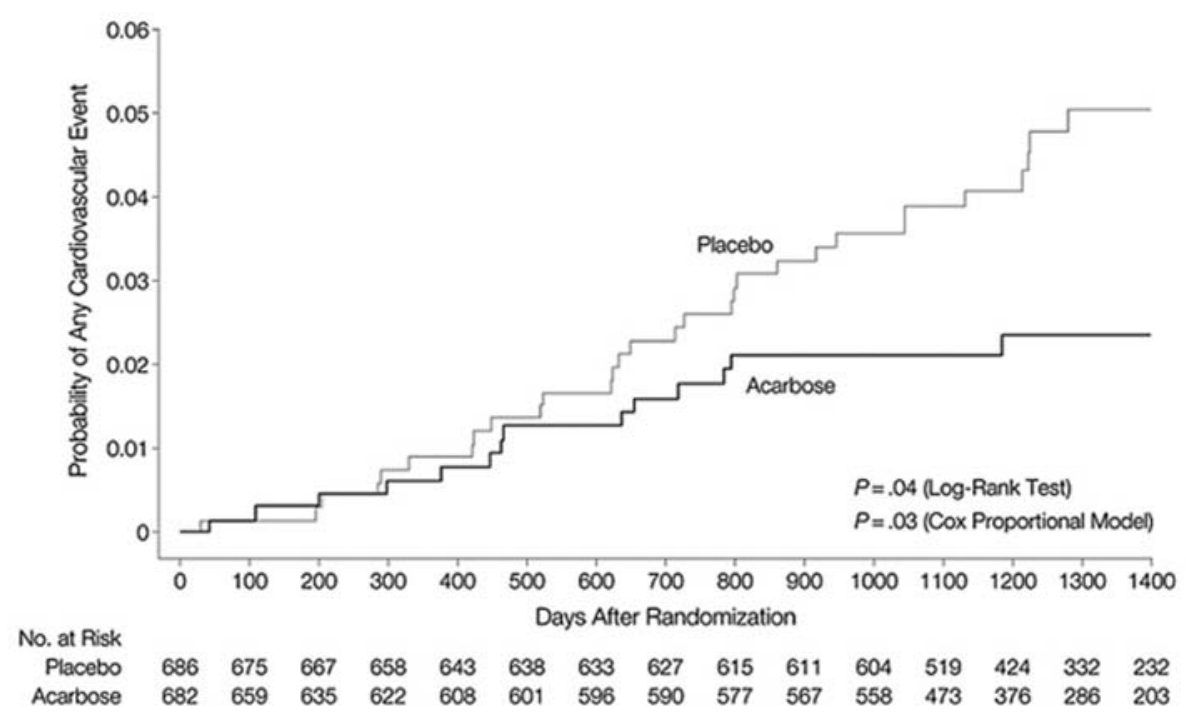

Figure 4. Effect of acarbose on the probability of remaining free of cardiovascular disease. [Chiasson et al. JAMA 2003;290:486-94 (ref. 41)]. 


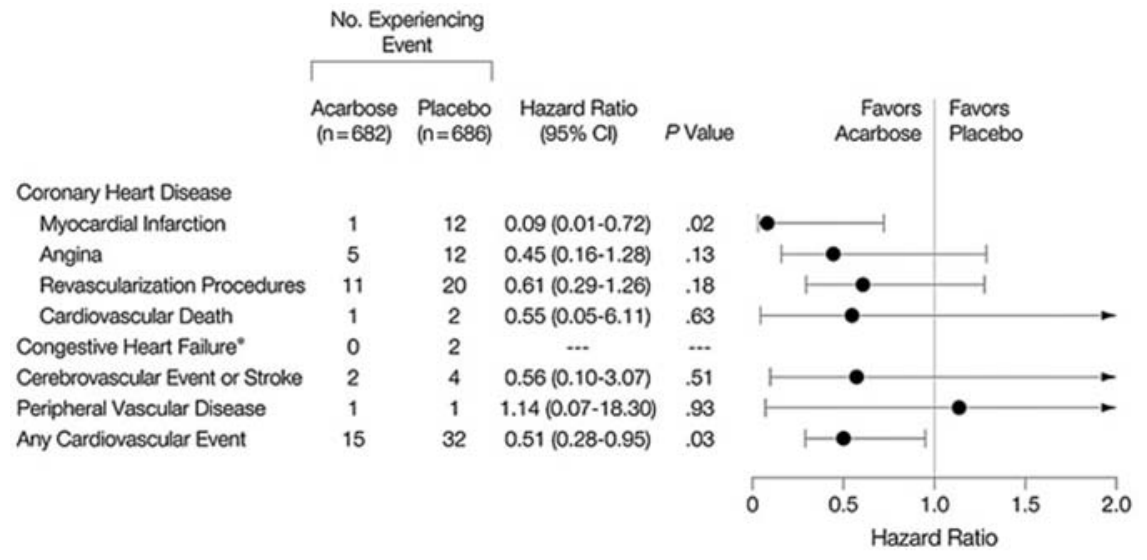

Figure 5. Effect of acarbose on the development of cardiovascular sisease. [Chiasson et al. JAMA 2003;290:486-94].

$\mathrm{Cl}=$ confidence interval. Asterisk indicates hazard ratio $(95 \% \mathrm{Cl})$ could not be calculated because of zero event for acarbose group.

tion in the development of new cases of hypertension and a $49 \%$ risk reduction in cardiovascular events (41). In addition, in a subgroup of patients, acarbose treatment was associated with a significant decrease in the progression of carotid intima-media thickness, previously indicated as a surrogate for atherosclerosis (42).

The effects of two insulin secretagogues, repaglinide and glibenclamide (glyburide), known to have different efficacy on postprandial hyperglycemia, were given to drug-naïve DM2 patients, in a randomized single-blind trial, after a titration period of 6 to 8 weeks, to evaluate carotid intima-media thickness and markers of systemic vascular inflammation (43). Repaglinide is a rapid-onset/short- duration insulinotropic agent, whereas glybenclamide is a longacting sulfonylurea. Repaglinide selectively increases meal-related early insulin secretion and may result in a better control of postprandial hyperglycemia than glibenclamide (44). After 12 months, postprandial glucose peak was $148 \pm 28 \mathrm{mg} / \mathrm{dl}($ mean $\pm S D)$ in the repaglinide group and $180 \pm 32 \mathrm{mg} / \mathrm{dl}$ in the glibenclamide group $(\mathrm{P}<0.01)$. HbAlc showed similar decrease in both groups $(-0.9 \%)$. Carotid intima-media thickness regression was observed in $52 \%$ of diabetic subjects receiving repaglinide and in $18 \%$ of those receiving glibenclamide $(\mathrm{P}<0.01)$. Interleukin-6 $(\mathrm{P}=$ $0.04)$ and $\mathrm{C}$-reactive protein $(\mathrm{P}=0.02)$ decreased more in the repaglinide group than in the glibenclamide group. The reduction in carotid intima-media thickness was associated with changes in postprandial, but not fasting hyperglycemia, suggesting that treating postprandial hyperglycemia may positively affect the development of CVD (43).
A similar study was performed in 8 DM2 patients on two different occasions when they received an oral glucose load $(50 \mathrm{~g})$ preceded by either human regular insulin, reaching a peak of $259 \pm 22 \mathrm{mg} / \mathrm{dl}$ at $100 \mathrm{~min}$., or rapid but short-acting insulin lispro, the peak being earlier $(80 \mathrm{~min})$ and lower $(229 \pm 27$ $\mathrm{mg} / \mathrm{dl} ; \mathrm{P}<0.01$ ), both given in a dose of $0.075 \mathrm{U} / \mathrm{kg}$ lean body mass (45). Basal plasma glucose, insulin and endogenous glucose production were similar in both occasions. After the ingestion of plasma glucose, the incremental glucose area under the curve was $46 \%$ lower with lispro in comparison with regular insulin $(\mathrm{P}<0.01)$. However, in spite of comparable incremental areas of plasma insulin under the curve, the time course of plasma insulin concentration was significantly different: after regular insulin, plasma insulin peaked at $120 \mathrm{~min}$. while with lispro the peak occurred at 60 min. with higher insulin levels. Plasma glucose kinetics indicated no difference in the two studies in the rate of appearance of ingested glucose and in the overall rate of glucose disposal. During the initial 90 min., however, the rate of endogenous glucose production was suppressed in a prompter and more profound manner when lispro was administered $(\mathrm{P}<0.05)$, while there was no difference in the late prandial phase. The AA (45) concluded that an early rise in plasma insulin levels after the ingestion of glucose load is associated with a significant improvement in glucose tolerance due to a prompter, though short-lived, suppression of endogenous glucose production. The amelioration in plasma glucose profile prevents late hyperglycemia and hyperinsulinemia. Therefore, restoration of a more physiologic profile of prandial plasma insulin profile 


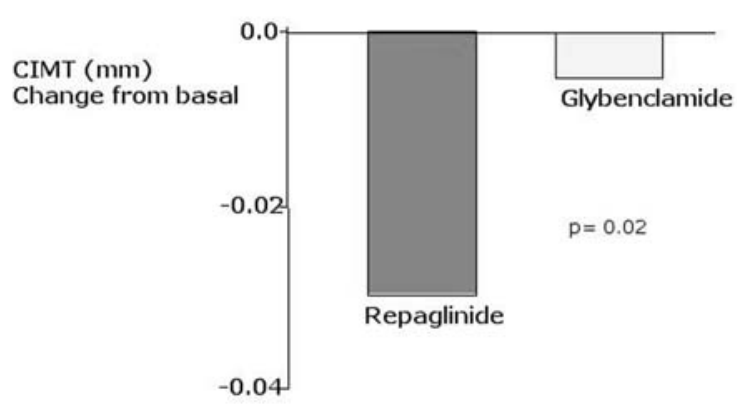

Figure 6. Atherosclerosis regression in the carotid* after post-prandial glucose control in type 2 diabetic patients. [Esposito K et al. Circulation 2004;110:214-9 (ref. 43)].

* CIMT reduction after 12 months (CIMT= carotid intimamedia thickness)

represents a rational approach for treatment of postprandial hyperglycemia.

New antidiabetic drugs, such as incretin mimetics and incretin enhancers target the suppression of postprandial hyperglycemia. In effect, glucagon-like peptide-1 (GLP-1) receptor agonists (mimetics) enhance insulin release when glucose concentrations are elevated, suppress postprandial glucagon secretion, in addition to slowing gastric emptying and promoting satiety (46). The significant attenuation of post-meal hyperglycemia after the incretin mimetic (exenatide) injection was related to the reduction in the rate of oral glucose appearance in the systemic circulation and enhancement of the suppression of endogenous glucose production: half of the decrease in endogenous glucose production results from the inhibition of glucagon secretion and half from increased insulin secretion (47). It was also shown that the incretin mimetics enhanced postprandial beta-cell function in patients with DM2 treated with metformin or metformin and sulfonylurea $(48,49)$.

Finally, the dipeptidyl peptidase-IV inhibitors, preventing the degradation of native GLP-1 have emerged as a therapeutic strategy for enhancing GLP$\mathrm{l}$ action in vivo (incretin enhancers), particularly as they can be taken orally, in a once-daily dosing regimen. Presently two DPP-IV inhibitors, Sitagliptin (Januvia) and Vildagliptin (Galvus) will be commercially available shortly.

The effects of DDP-IV inhibition could be mediated not only by GLP-1, but also by other mediators of the glucose-lowering actions of DPP-IV inhibition in clinical studies, since it causes little increase in circulating endogenous GLP-1 (while GLP-1 receptor
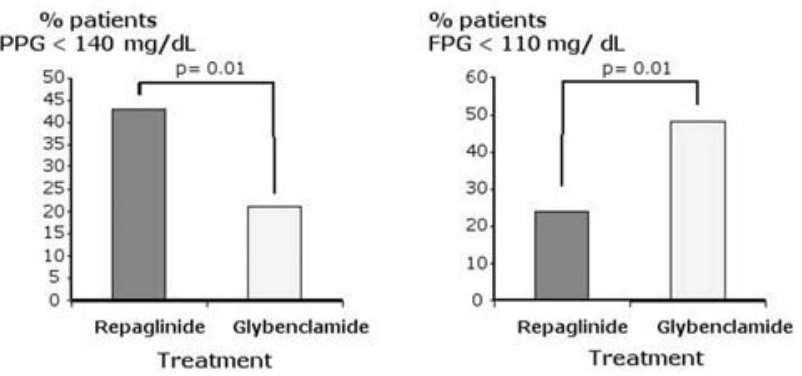

Figure 7. Reduction in CIMT is associated with changes postprandial (PPG) but not with fasting (FPG) glucose. [Esposito K et al. Circulation 2004;110:214-9 (ref. 43)].

$\mathrm{CIMT}=$ carotid intima-media thickness

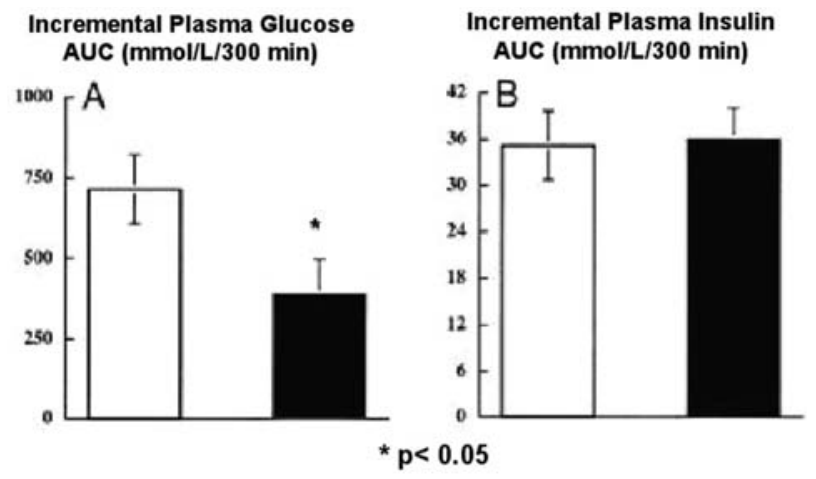

Figure 8. $A \cup C^{*}$ of plasma glucose $(A)$ and insulin (B) after oral $50 \mathrm{~g}$ of glucose preceded by $0.075 \mathrm{U} / \mathrm{kg} \mathrm{LBM}^{* *}$ of regular ( $\square$ ) and lispro ( $\square$ ) insulin. [Bruttomesso et al. Diabetes 1999;48:99-105 (ref. 45)].

* AUC: Area under the curve; ** LBM: Lean Body mass

agonists the effect corresponds to that of pharmacological concentrations of native GLP-1), has little effect on gastric emptying, does not cause nausea/vomiting like GLP-1 and GLP-1 agonists and it is not associated with weight loss (50). As indicated with the incretin mimetics, both enhancers have similar clinical efficiency in reducing postprandial glucose excursions by improving beta-cell function with enhanced postprandial insulin secretion.

The epidemiological and intervention studies presented in the article support the conclusion that postprandial hyperglycemia in impaired glucose tolerance and diabetic subjects is a more powerful marker of CVD risk than fasting hyperglycemia, then the treatment directed at specifically lowering postprandial glucose is crucial, as underlined by the American Diabetes Association (1). 

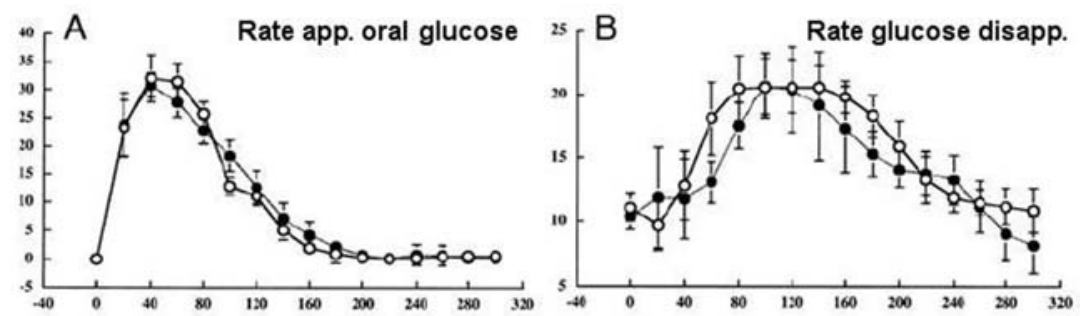

Rates: $\mu \mathrm{mol} / \mathbf{k g} / \mathrm{min}$

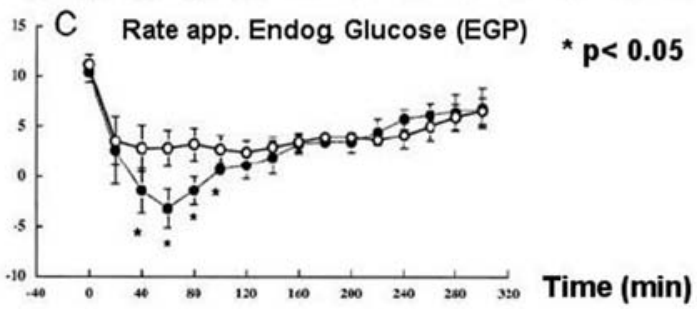

Figure 9. Time course of rate app. oral glucose (A), glucose disapp. (B), and rate of EGP (C) after oral $50 \mathrm{~g}$ of glucose preceded by $0.075 \mathrm{U} / \mathrm{kg} \mathrm{LBM}$ * of regular (O) and lispro (๑) insulin. [Bruttomesso et al. Diabetes 1999;48:99-105 (ref. 45)].

* LBM: Lean Body mass

\section{REFERENCES}

1. American Diabetes Association. Postprandial blood glucose. Diabetes Care 2001;24:775-8.

2. UK Prospective Diabetes Study (UKPDS) Group. Intensive blood-glucose control with sulphonylureas or insulin compared with conventional treatment and risk of complications in patients with type 2 diabetes(UKPDS 33). Lancet 1998;352:837-53.

3. Avignon A, Radauceanu A, Monnier L. Nonfasting plasma glucose is a better marker of diabetic control than fasting plasma glucose in type 2 Diabetes. Diabetes Care 1997;20:1822-6.

4. El-Kebbi JM, Ziemer DC, Cook CB, Gallina DL, Barnes CS, Phillips LS. Utility of casual postprandial glucose levels in type 2 diabetes management. Diabetes Care 2004; 27:335-9.

5. Rohlfing CL, Wiemeyer HM, Little RR, England JD, Tennill A, Goldstein DE. Defining the relationship between plasma glucose and $\mathrm{HbA}(1 \mathrm{c})$ : analysis of glucose profiles and $\mathrm{HbA}(1 \mathrm{c})$ in the Diabetes Control and Complications Trial. Diabetes Care 2002;25:275-8.

6. Kannel WB, McGee DL. Diabetes and cardiovascular disease. The Framingham study. JAMA 1979;241:2035-8.

7. Lehto S, Ronnemaa T, Pyorala K, Laakso M. Cardiovascular risk factors clustering with endogenous hyperinsulinemia predict death from coronary heart disease in patients with Type II diabetes. Diabetologia 2000;43:148-55.

8. Dahl-Jorgensen K, Larsen JR, Hanssen KF. Atherosclerosis in childhood and adolescent type 1 diabetes: early disease, early treatment. Diabetologia 2005;48:1445-53.

9. Bierman EL. Atherogenesis in diabetes. Arterioscler Thromb 1992;12:647-56.

10. Laakso M. Hyperglycemia and cardiovascular disease in type 2 diabetes. Diabetes 1999;48:937-42.

11. Monnier $L$, Colette $C$. Contributions of fasting and postprandial glucose to hemoglobin A1c. Endocr Pract 2006;12(suppl 1):42-6.

12. Bell DS. Importance of postprandial glucose control. South Med J 2001;94:804-9.

13. Heine RJ, Dekker JM. Beyond postprandial hyperglycemia: metabolic factors associated with cardiovascular disease. Diabetologia 2002;45:461-75.
14. Coutinho M, Gerstein HC, Wang Y, Yusuf S. The relationship between glucose and incident cardiovascular events. A metaregression analysis of published data from 20 studies of 95,783 individuals followed for 12.4 years. Diabetes Care 1999;22:233-40.

15. Gerstein HC. Is glucose a continuous risk factor for cardiovascular mortality? Diabetes Care 1999;22;659-60.

16. Khaw K-T, Wareham N, Bingham S, Luben R, Welch A, Day N. Association of Hemoglobin A1c and cardiovascular disease and mortality in adults: the European Prospective Investigation into Cancer in Norfolk. Ann Intern Med 2004; 141:413-20.

17. Barrett-Connor E, Ferrara A. Isolated postchallenge hyperglycemia and the risk of fatal cardiovascular in older women and men. The Rancho Bernardo Study. Diabetes Care 1998;21:1236-9.

18. Abdul-Ghani MA, Tripathy D, DeFronzo RA. Contributions of $\beta$-cell dysfunction and insulin resistance to the pathogenesis of impaired glucose tolerance and impaired fasting glucose. Diabetes Care 2006;29:1130-9.

19. Meyer C, Pimenta W, Woerle HJ, Haeften TV, Szose E, Mitrakou A, et al. Different mechanisms for Impaired fasting Glucose and Impaired postprandial glucose tolerance in humans. Diabetes Care 2006;29:1909-14.

20. Mitrakou A, Kelley D, Mokan M, Veneman T, Pangburn T, Reilly J, et al. Role of reduced suppression of glucose production and diminished early insulin release in Impaired glucose tolerance. N Engl J Med 1992;326:22-9.

21. Ceriello A. Postprandial hyperglycemia and diabetes complications. Is it time to treat? Diabetes 2005;54:1-7.

22. Teno $S$, Uto $Y$, Nagashima $H$, Endoh $Y$, Iwamoto $Y$, Omori $Y$, et al. Association of postprandial hypertriglyceridemia and carotid intima-media thickness in patients with type 2 diabetes. Diabetes Care 2000;23:1401-6.

23. Iovine C, Vaccaro O, Gentile A, Romano G, Pisanti F, Riccardi $\mathrm{G}$, et al. Post-prandial triglyceride profile in a populationbased sample of Type 2 diabetic patients. Diabetologia 2004; $47: 19-22$.

24. Ceriello A, Motz E. Is oxidative stress the pathogenic mechanism underlying insulin resistance, diabetes, and cardiovascular disease? The common soil hypothesis revisited. Arterioscler Thromb Vasc Biol 2004;24:816-23.

25. Hokanson JE, Austin MA. Plasma triglyceride level is a risk factor for cardiovascular disease independent of high-density 
lipoprotein cholesterol level: a meta-analysis of populationbased prospective studies. J Cardiovasc Risk 1996;3:2139.

26. Stampfer MJ, Krauss RM, Ma J, Blanche PJ, Holl Lg, Sacks FM, et al. A prospective study of triglyceride level, low-density lipoprotein particle diameter, and risk of myocardial infarction. JAMA 1999;276:882-8.

27. Wolever TMS, Chiasson JL, Csima A, Hunt JA, Palmason C, Ross SA, et al. Variation of postprandial plasma glucose, palatability, and symptoms associated with a standardized mixed meal versus $75 \mathrm{~g}$ oral glucose. Diabetes Care 1998;21:336-40.

28. de Vegt F, Dekker JM, Ruhè HG, Stehouwer CDA, Nijpels GBLM, Heine RJ. Hyperglycemia is associated with all-cause and cardiovascular mortality in the Hoorn population: the Hoorn Study. Diabetologia 1999;42:926-31.

29. Donahue RP, Abbott RD, Reed DM, Yano K. Postchallenge glucose concentration and coronary heart disease in men of Japanese ancestry: Honolulu Heart Program. Diabetes 1997;36:689-92.

30. Lowe LP, Liu K, Greenland P, Metzger BE, Dyer AR, Stamler J. Diabetes, asymptomatic hyperglycemia, and 22-year mortality in black and white men: the Chicago Heart Association Detection Project in Industry study. Diabetes Care 1997;20:163-9.

31. The DECODE Study Group, the European Diabetes Epidemiology Group. Glucose tolerance and mortality: comparison of WHO and American Diabetes Association diagnostic criteria. Lancet 1999;354:617-21.

32. The DECODE study group on behalf of the European Diabetes Epidemiology Group. Glucose tolerance and cardiovascular mortality. Comparison of fasting and 2-h diagnostic criteria. Arch Intern Med 2001; 161:397-404.

33. Balkau B, Shipley $M$, Jarrett RJ, Pyörälla K, Pyörälla M, Forhan A, et al. High blood glucose concentration is a risk factor for mortality in middle-aged nondiabetic men: 20-year follow-up in the Whitehall Study, the Paris Prospective Study, and the Helsinki Policemen Study. Diabetes Care 1998;21:360-7.

34. Hanefeld M, Fischer S, Julius U, Schulze J, Schwanebeck U, Schmechel H, et al; the DIS Group. Risk factors for myocardial infarction and death in newly detected NIDDM: the Diabetes Intervention Study, a 11-year follow-up. Diabetologia 1996;39:1577-83.

35. Hanenfeld M, Koehler C, Schaper F, Fuecker K, Henkel E, Temelkova-Kurktschiev T. Postprandial plasma glucose is an independent risk factor for increased carotid intima-media thickness in non-diabetic individuals. Atherosclerosis 1999;144:229-35.

36. Brownlee M. The pathobiology of diabetic complications. A unifying mechanism. Diabetes 2005;54:1615-25.

37. Koya D, King GL. Protein kinase C activation and the development of diabetic complications. Diabetes 1998;47:859-66.

38. Vinik $A$. The protein kinase $C-\beta$ inhibitor, ruboxistaurin, for the treatment of diabetic microvascular complications. Expert Opin Investig Drugs 2005;14:1547-59.
39. Report of the Expert Committee on the Diagnosis and Classification of Diabetes Mellitus. Diabetes Care 1998;22(suppl. 1):S5-S19.

40. Chiasson JL, Josse RG, Gomis R, Hanefeld M, Karasik A, Laakso M; the STOP-NIDDM Trial Research Group. Acarbose for prevention of type 2 diabetes: the STOP-NIDDM randomized trial. Lancet 2002;359:2072-7.

41. Chiasson JL, Josse RG, Gomis R, Hanefeld M, Karasik A, Laakso M; the STOP-NIDDM Trial Research Group. Acarbose treatment and the risk of cardiovascular disease and hypertension in patients with impaired glucose tolerance: the STOP-NIDDM trial. JAMA 2003;290:486-94.

42. Hanefeld M, Chiasson JL, Koehler C, Henkel E, Schaper F, Temelkova-Kurktschiev T. Acarbose slows progression of intima-media thickness of the carotid arteries in subjects with impaired glucose tolerance. Stroke 2004;35:1073-8.

43. Esposito K, Giugliano D, Nappo F, Marfella R; for the Campanian Post-prandial Hyperglycemia Study Group. Regression of carotid atherosclerosis by control of postprandial hyperglycemia in type 2 diabetes mellitus. Circulation 2004; 110:214-9.

44. Cozma LS, Luzio SD, Dunseath GJ, Langendorg KW, Pieber T, Owens DR. Comparison of the effects of three insulinotropic drugs on plasma insulin levels after a standard meal. Diabetes Care 2002;25:1271-6.

45. Bruttomesso D, Pianta A, Mari A, Valerio A, Marescotti M-C, Avogaro A, et al. Restoration of early rise in plasma insulin levels improves the glucose tolerance of type 2 diabetic patients. Diabetes 1999;48:99-105.

46. Baggio LL, Drucker DJ. Incretin hormones in the treatment of type 2 diabetes: Therapeutic applications of DPP-IV inhibitors. Medscape Diabetes Endocrinol 2006;8:1-5.

47. Wajcberg E, Triplitt C, Sriwijitkamol A, De Fronzo R, Cerosimo E. Contribution of glucagon suppression to improved postprandial hyperglycemia induced by exenatide in patients with TT2MM [Abstract 118-OR]. Diabetes 2006;55(suppl 1);A28.

48. Mari A, Halseth A, Nanayakkara N, Nielsen L, DeFronzo R, Ferrannini E. Mathematical modeling shows exenatide improved postprandial $\beta$-cell function in patients with type 2 diabetes treated with metformin or metformin and sulfonylurea [Abstract 482-P]. Diabetes 2005;54(suppl. 1);A119.

49. Mari A, Degn K, Brock B, Rungby J, Ferrannini E, Schmitz O. Characterization of beta-cell function improvement by liraglutide: modeling analysis of 24-h tests [Abstract $522-P$ ]. Diabetes 2006;55(suppl. 1):A124.

50. Drucker DJ. DPP-4 inhibitors in the management of type 2 diabetes. Mechanisms in Medicine Inc., 2006. p. 59.

Endereço para correspondência:

Bernardo Léo Wajchenberg

Rua Itapeva 490 - $5^{\circ}$ andar

01332-902 São Paulo, SP 